Sulphanilylguanidine probably owes much of its effectiveness as an intestinal antiseptic to its poor absorption from the intestine, since one-half to two-thirds of the drug remains unabsorbed.

Blood and urinary concentrations of the drug were low relative to the dosage given, and toxic effects were conspicuous by their absence. Since crystalline deposits occur in the urine with concentrations over $175 \mathrm{mg}$. per $100 \mathrm{c.cm}$., an adequate fluid intake and output should be maintained to avoid local toxicity or irritation in the urinary tract, although there was no evidence of any such effect in this series of treated cases.

The use of a new culture medium, desoxycholate-citrate agar, resulted in the isolation of $B$. dysenteriae (Flexner) from a high proportion of both typical and atypical infections. Its superiority over MacConkey's medium was most noticeable in the isolation of the pathogen during convalescence.

The combination of an efficient intestinal antiseptic and a culture medium which will readily detect mild infections and convalescent carriers may be instrumental in eliminating dysentery from mental hospitals

We wish to thank Dr. G. A. Lilly, medical superintendent of Cane Hill Hospital, for facilities and encouragement throughout this investigation, and the technical staff of the hospital and group laboratories for their help.

REFERENCES

Bell, G. J. (1941). Lancet, 2, 101

Bell, G. J. (1941). Lancet, 2, 10 (1940), Ibid, 2,803

Cruickshank, R., and Swyer, R. (1940). 16id.,

Hynes, M. (1940). Lancet, 1, 261.

Hynes, M. (1940). Lancel, 1, 261. $40,581$.

Leifson, E. E K Bratton A C White, H. J., and Litchfield, J. T. (1940) Johns Hopk. Hosp. Bull. 67 , 163 .

Hopk. Hosp. Bull., 67, 163.

Reitler, R., and Marberg, K. (1941). British Medical Journal, 1, 277.

\section{THE PREPARATION OF SULPHANILYLGUANIDINE}

It appears that sulphanilylguanidine (I) was first obtained by Buttle et al. (1938), who, from its mode of formation, unwittingly ascribed an erroneous constitution to their product (Dewing and Smith, 1941). The compound was first described as such by Roblin and his co-workers (1940), who encountered it accidentally in the course of their study of the synthesis of heterocyclic derivatives of sulphanilamide. These authors, for identification purposes, then obtained the substance by reduction of the nitro group in $p$-nitrobenzenesulphonylguanidine (II), which they synthesized (cf. Winnek, 1940, 1941). A few weeks later Marshall and his colleagues (1940) published a description of a largescale preparation of sulphanilylguanidine, and their method was followed in the present work. Condensation of acetylsulphanilyl chloride with guanidine nitrate in the presence of a large excess of sodium hydroxide yields acetylsulphanilylguanidine (III), which is subsequently hydrolysed with hydrochloric acid to free sulphanilylguanidine:

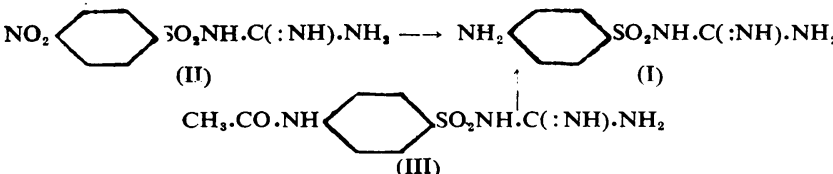

Two points of interest emerge and deserve comment. As obtained initially, the acetylsulphanilylguanidine (III) forms a somewhat pasty white solid which tenaciously retains water. Drying is a very slow process under the ordinary conditions (hot oven at $90^{\circ} \mathrm{C}$., or vacuum desiccator, etc.), and furnishes apparent yields of the same order as those quoted by Marshall et al.--namely, 65 to $70 \%$ of theory. Hydrolysis of this product yielded free sulphanilylguanidine also in the amount reported by Marshall et al.-namely, 45 to $60 \%$ of theory. The process of drying can, however, be greatly accelerated by washing the cake of crude acetyl derivative on the filter with small volumes of spirit and then ether, in which solvents the compound is insoluble. Drying in the hot oven at $90^{\circ} \mathrm{C}$. then gives an absolutely dry product in an hour or two, and, on account of the more efficient drying, the yields obtained at this stage appear to be somewhat smallernamely, 59 to $62 \%$ of theory. On the other hand, hydrolysis of the acetyl derivative dried in this way gave free sulphanilylguanidine in the improved amounts of 61 to $72 \%$ of theory.

Tests for acute and chronic toxicity of this preparation on mice gave results very similar to those reported by Marshall et al. (1940).

\section{REFERENCES}

Buttle, G. A. H., Dewing, T., Foster, G. E., Gray, W. H., Smith, S., and Stephenson, D. (1938). Biochem. J., 32, 1101.

Dewing, T., and Smith, S. (1941) Nature, 148, 24. Marshall, E. K., Bratton, A. C.

Roblin, R. O., Williams, J. H., Winnek, P. S., and English, J. P. (1940). J. Ame chem. Soc., 62, 2002 .

Winnek, P. S. (1940). U.S. Patent 2,218,490.

(1941). U.S. Patent 2229784 ; also, U.S. Patents 2230875 and 2233569

\section{A TELLURITE-IRON-ROSOLIC ACID MEDIUM SELECTIVE FOR B. DYSENTERIAE (FLEXNER)}

BY

W. JAMES WILSON, M.D., D.Sc.

AND

E. M. McV. BLAIR, M.Sc., Ph.D.

(From Public Health Laboratories, Queen's University, Belfast)

Dysentery bacilli, unlike those of the typhoid-paratyphoid groups, have not shown any peculiar characters enabling the investigator to devise a medium which, while inhibiting the growth of other organisms, allows them to develop and be readily identified.

On litmus lactose agar and on the media of MacConkey, Conradi-Drigalski, and Endo the unrestrained growth of $B$. coli leaves little place on the plates for the development of dysentery bacilli, so that their successful isolation is usually possible only in the early acute stages of the disease and when the stools are planted out within a few hours of their collection. To the antiseptic action of such dyes as malachite green, methyl green, victoria green, brilliant green, fuchsin, crystal violet, and gentian violet dysentery bacilli are more sensitive than most strains of $B$. coli (Churchman, 1912, 1913 ; Krumwiede and Pratt, 1914 ; Kligler, 1918). The new Difco Bacto S S agar specially devised for the isolation of Salmonella and Shigella strains is designed to meet a long-felt want, a want which may also be satisfied by the medium described in this paper.

\section{The Action of Sodium Tellurite}

In the course of an investigation of the suitability of a modified bismuth sulphite medium for the selective growth of Flexner's bacillus, addition of sodium tellurite was found to reduce the growth-inhibitory action both of the bismuth and of the tellurite.

We have shown in the development of our bismuth sulphite medium that the addition of iron salts enabled the $B$. typhosus to develop while the growth of many other organisms continued to be suppressed (Wilson and Blair, 1927). It was this experience which led us to try a combination of tellurite and a ferric iron salt. Having found the bismuth sulphite media unsuitable for use with tellurite, we tried the addition of tellurite to MacConkey's medium, and discovered that the addition of $0.5 \mathrm{c.cm}$. of a $1 \%$ watery solution of sodium tellurite to $100 \mathrm{c.cm}$. of the medium completely inhibited the growth of nine strains 
of $B$. lactis aerogenes and nineteen of twenty-one strains of $B$. coli, whilst all of six strains of Flexner's dysentery bacilli showed some growth, varying from a few isolated colonies to confluent growth. It was clear that tellurite showed .possibilities of being used in a medium selective for Flexner bacilli. However, the concentration necessary for the suppression of $B$. coli was sufficient to prevent the growth of all but the most resistant strains of $B$. dysenteriae (Flexner) ; in other words, instead of hundreds of colonies or a confluent growth, only a few isolated colonies developed. It was then found that the addition of $2 \mathrm{c.cm}$. of a $4 \%$ watery solution of iron citrate scales to $100 \mathrm{c.cm}$. of the MacConkey tellurite medium allowed a rich growth of the dysentery bacilli and that the suppression of $B$. coli continued. How the iron salt acts, whether by precipitating some of the tellurite or by a process of oxidation, is uncertain. It would seem that the iron salt converts the tellurite into a form which permits rich growth of Flexner bacilli and yet inhibits the growth of $B$. coli to a very large extent. There is an optimum proportion in the ratio of tellurite to iron, and as the result of numerous experiments we found that for 0.5 to $1 \mathrm{c} . \mathrm{cm}$. of a $1 \%$ potassium tellurite solution the amount of a $4 \%$ watery solution of iron citrate should be $2 \mathrm{c} . \mathrm{cm}$., or of a $4 \%$ watery solution of iron alum $1 \mathrm{c} . \mathrm{cm}$. $\left(\mathrm{K}_{2} \mathrm{SO}_{1} \mathrm{Fe}_{2}\left(\mathrm{SO}_{4}\right)_{3} \cdot 24 \cdot \mathrm{H}_{2} \mathrm{O}\right)$. The basis of our medium is ordinary nutrient agar consisting of distilled water $1,000 \mathrm{c.cm}$., peptone 10 grammes, Lemco 5 grammes, sodium chloride 5 grammes, powdered agar 20 grammes. The reaction is adjusted to $p \mathrm{H} \mathrm{7.4}$. The nutrient agar is sterilized under pressure and is not filtered.

\section{Constituents of the Medium Used}

A medium which we employed in many of our experiments, and with which we were successful in isolating Flexner dysentery bacilli from two samples of faeces sent by post, is made as follows :

0.5 gramme of sodium tauroglycocholate and 0.5 gramme of lactose are dissolved in about $10 \mathrm{c.cm}$. of boiling water in a $100-c . c m$. wide-necked flat-bottomed extraction flask; then melted nutrient agar cooled to $60^{\circ} \mathrm{C}$. is added up to the $100 \mathrm{c} . \mathrm{cm}$. mark, followed by $0.5 \mathrm{c} . \mathrm{cm}$. of $1 \%$ potassium tellurite, $2 \mathrm{c.cm}$. of $4 \%$ iron citrate, and $0.5 \mathrm{c} . \mathrm{cm}$. of $1 \%$ neutral red watery solution.

On the surface of this medium colonies of Flexner's bacillus are yellowish, and any strains of $B$. coli that are not suppressed are reddish. In practice we found that stools which show few colonies of Streptococcus faecalis on ordinary MacConkey provided abundant tiny colonies on this medium. There was no danger of confusing these colonies and those of Flexner, but it was obvious that their suppression would be a great advantage. After numerous trials of various substances we found that the addition of $0.5 \mathrm{c} . \mathrm{cm}$. of $1 \%$ rosolic acid dissolved in absolute alcohol to $100 \mathrm{c.cm}$. of the tellurite medium secured the desired result. This suppression of Str. faecalis by rosolic acid we have confirmed by the examination of over sixty stools and the employment of pure cultures of Str. faecalis. Our results confirm those of Bronfenbrenner, Schlesinger, and Soletsky obtained in 1920. These authors found that rosolic acid, or a mixture of rosolic acid and china blue, when added to $100 \mathrm{c.cm}$. of media to the extent of $0.25 \mathrm{c.cm}$. of a $2 \%$ solution of rosolic acid in $50 \%$ alcohol, allowed the growth of colon, typhoid, and dysentery bacilli while suppressing that of Gram-positive bacteria, including Str. faecalis.

In our medium the tellurite-iron complex inhibits many coliform organisms, but allows rich growth of Flexner's dysentery bacilli, and the rosolic acid acts not only as an indicator but as an agent for the suppression of Str. faecalis and other Gram-positive bacteria. The tellurite-ironrosolic acid medium is highly selective for Flexner's dysentery bacilli. On this medium the growth of typhoidparatyphoid bacilli, Sonne's bacillus, and cholera vibrios is completely suppressed, as is that of twenty strains of Salmonella food-poisoning organisms kindly supplied to us by Dr. St. John-Brooks from the National Collection; these included such strains as aertrycke (mutton), chester, chaco, berlin, binns, derby, dublin, heidelberg, hirschfeld para $\mathrm{C}$, kapsover, kunzendorf, morbificans-bovis, london, limerick, newport, panama, stanley, senftenberg. The growth of most strains of $B$. coli and $B$. lactis aerogenes is completely inhibited or is very scanty.

In the recent examination of fifty stools we found that heavy inocula of faecal emulsions did not, as on MacConkey plates, lead to confluent growth of $B$. coli but to the formation of discrete colonies, which were sometimes few and sometimes numerous. There was no difficulty in isolating the dysentery bacillus when it was mixed with the faecal emulsion. On the medium few non-lactosefermenting bacteria developed, apart from Flexner's dysentery bacilli; such as developed have been found to belong to the Proteus, Alcaligenes, and Pyocyaneus groups, and can be distinguished from dysentery bacilli in that they form pink colonies, larger, more raised, and with a centre more opaque than that of the more translucent colonies of Flexner's bacillus.

\section{Experimental Technique}

In our experiments we employed five strains of Flexner's bacillus ( $\mathrm{V}, \mathrm{W}, \mathrm{X}, \mathrm{Y}, \mathrm{Z})$ obtained from the National Collection of Type Cultures and five strains recently isolated in Northern Ireland. All the strains grew well on the medium which for some time past we have found most satisfactory. It is prepared as follows:

To $100 \mathrm{c.cm}$. of melted nutrient agar cooled to $60^{\circ} \mathrm{C}$. in a flask are added $0.5 \mathrm{c.cm}$. of $1 \%$ rosolic acid dissolved in absolute alcohol, $1 \mathrm{c:cm}$. of a $4 \%$ watery solution of iron alum, and finally $3 \mathrm{c.cm}$. of a lactose-tellurite solution. The latter solution is made by boiling 20 grammes of lactose in $100 \mathrm{c.cm}$. of distilled water, cooling the solution, and then dissolving in it 0.2 gramme of potassium tellurite. It is necessary to dissolve the tellurite in the cold, otherwise reduction occurs. This lactosetellurite solution keeps for weeks, the tellurite being an effective preservative against bacteria, but not against moulds: growth of the latter can be prevented by the addition of $3 \%$ of ether and keeping the bottle tightly stoppered.

When the contents of the flask containing the medium have been thoroughly mixed they are poured out into Petri dishes and allowed to set with the lids removed. A large loopful of a thick faecal emulsion in peptone water is spread over the surface of the plate and allowed to dry in the air. After incubation at $37^{\circ} \mathrm{C}$. for eighteen hours the pink colonies of Flexner's bacillus are readily distinguished from any yellow colonies of resistant $B$. coli which may have developed. Flexner's bacillus forms alkali and the colony becomes distinctly pinkish red. In most cases the growth can be tested at once on a slide for agglutination with a polyvalent Flexner agglutinating serum. It is also easy to subculture suspicious colonies on to MacConkey's agar and test the agglutinability of the growth. For further proof of the nature of the organism, cultures are made in small test tubes containing mannite and glucose dissolved in peptone water with Andrade's reagent as indicator; the addition to these tubes of agar melted and cooled to $45^{\circ} \mathrm{C}$. is a ready method of detecting the absence of gas formation.

When this paper was being completed two stools containing blood and mucus arrived, having been posted the 
previous day. Both of these specimens on the telluriteiron-rosolic acid medium showed hundreds of colonies of Flexner's bacillus and absolutely no $B$. coli, whereas the same emulsion on MacConkey's plates yielded a profuse growth of $B$. coli and no recognizable colonies of $B$. dysenteriae.

\section{Summary}

Lactose nutrient agar containing, per $100 \mathrm{c.cm} ., 0.5 \mathrm{c.cm}$. of a $1 \%$ alcoholic solution of rosolic acid, $0.5 \mathrm{c.cm}$. of a $1 \%$ solution of potassium tellurite, and $1 \mathrm{c.cm}$. of a $4 \%$ solution of iron alum provides a medium on which Flexner's $B$. dysenteriae grows profusely, whereas there is great inhibition of most strains of $B$. coli and $B$. lactis aerogenes. The growth of Salmonella food-poisoning organisms, typhoid and paratyphoid bacilli, Sonne's bacillus, and cholera vibrios is suppressed.

\section{REFERENCES}

Bronfenbrenner, J., Schlesinger, M. J., and Soletsky, D. (1920). J. Bact., 5, 79 Churchman, J. W. (1912). J. exp. Med., 16, 221.

(1913). Ibid., 17, 373.

Kligler, I. J. (1918). Ibid., 27, 463.

Krumwiede, C., and Pratt, J. S. (1914). Ibid., 19, 501.

Wilson, W. J., and Blair, E. M. McV. (1927). J. Hyg., Camb., 26 ;374.

\section{A NEW SULPHONAMIDE (SULPHONAMIDE E.O.S.)}

ITS PHARMACOLOGY, CHEMOTHERAPY, AND CURATIVE VALUE IN MENINGOCOCCAL MENINGITIS

BY

\section{N. MUTCH, M.A., M.D., F.R.C.P.}

Senior Physician to Guy's Hospital; Sector Adviser in Medicine, E.M.S.; Director of Department of Therapeutics and Pharmacology, Guy's Hospital Medical School

Although some thousands of sulphonamide derivatives have now been prepared and investigated, very few have displayed any outstanding therapeutic qualities which would justify their general adoption in preference to the simple parent substance sulphanilamide or its popular variant sulphapyridine. The clinician desires something more than an active chemotherapeutic agent. He asks for the means of easy administration to patients of all ages and in all conditions and for freedom from side-actions which are either distressing or dangerous. The new compound employed in this investigation* is freely soluble in water, and $50 \% \mathrm{w} / \mathrm{v}$ solutions are easily obtained. It dissolves to form an almost tasteless preparation with a faintly acid reaction which can be reduced to one of absolute neutrality without precipitation or loss of stability. The treatment of infants and of fastidious, comatose, vomiting, or diarrhoeal patients is therefore easily carried out with solutions given by mouth, nasal tube, rectal tube, or intravenous drip. The familiar 0.5 gramme tablet can be reserved for routine use. In these respects it contrasts favourably with sulphanilamide, which is relatively insoluble in water, with sulphapyridine, which is much more insoluble still, and with sulphapyridine sodium, which, although freely soluble, forms a strongly alkaline solution approximately equivalent in reaction to decinormal caustic soda. Sulphonamide E.O.S. possesses the further attractive feature of low toxicity, and its administration does not lead to the formation of such highly insoluble bodies as the acetylated compounds, which tend to crystallize in the urinary passages when sulphapyridine or sulphathiazole is used (LeedhamGreen, 1941).

* The material used in this investigation was supplied by the Research Department of Imperial Chemical Industries Ltd.

\section{Chemistry and Fate in the Body}

The substance was first described by Green and Coplans (1940), who identify it as sulphonamide ethyl-alpha-sulphonate,

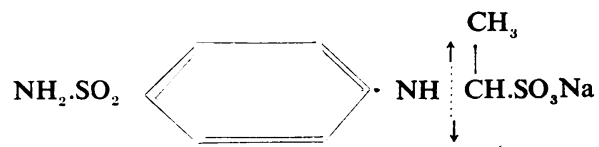

The side chain was chosen with two deliberate intentionsnamely, that of reducing the basicity of the original sulphanilamide and so reducing its toxicity, and that of furnishing a link (as indicated by the arrows) which could easily be broken in the body by hydrolysis, with the liberation of the parent nucleus. In aqueous solution it is stable at room temperature, but hydrolysis occurs on boiling, with the formation of sulphanilamide, acetaldehyde, and sodium bisulphite. Decomposition proceeds more quickly in the presence of acids or alkalis, and is accelerated very greatly indeed by oxidizing reagents such as iodine or hydrogen peroxide. Hydrolysis at body temperature and at $p H$ concentrations which are known to occur in the alimentary tract is relatively slow. The pertinent data given in Table I were furnished by the late Prof. A. G. Green.

TABLE I.-Hydrolysis of Sulphonamide E.O.S.

\begin{tabular}{|c|c|c|}
\hline \multicolumn{2}{|c|}{ Reaction of Solution ( $21 \%$ E.O.S.) } & $\begin{array}{c}\% \text { E.O.S. hydrolysed in } 3 \text { Hours } \\
\text { at } 37^{\circ} \mathrm{C} \text {. }\end{array}$ \\
\hline 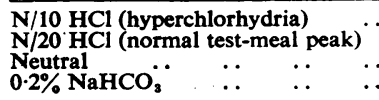 & $\begin{array}{l}. . \\
\ldots\end{array}$ & $\begin{array}{l}4 \cdot 0 \\
2 \cdot 8 \\
0 \cdot 7 \\
1 \cdot 8\end{array}$ \\
\hline
\end{tabular}

Throughout this range more than $95 \%$ of the drug remains unaffected at the end of three hours, and during this period a large proportion of the drug is absorbed. After absorption hydrolysis proceeds much more rapidly.

A $50 \%$ solution $\mathrm{w} / \mathrm{v}$ was injected intravenously (dose $5 \mathrm{c.cm}$. $=2.5$ grammes E.O.S.). Of this only $16 \%$ could be recovered unchanged from the urine, and even during the first thirty minutes about one-half was excreted as sulphanilamide or as acetyl-sulphanilamide, the side chain having been removed from the original drug (Table II).

TABLE II.-Intravenous Administration of Sulphonamide E.O.S. (Man). (Dose, 2.5 grammes in 5 c.cm.)

\begin{tabular}{c|c|c}
\hline & \multicolumn{2}{|c}{ Rate of Urinary Excretion } \\
\cline { 2 - 2 } $\begin{array}{c}\text { Interval after } \\
\text { Administration }\end{array}$ & $\begin{array}{c}\text { Unsplit } \\
\text { Sulphonamide E.O.S. } \\
\text { (Mg. per } \frac{1}{2} \text { hour) }\end{array}$ & $\begin{array}{c}\text { Total Sulphonamide, } \\
\text { expressed as } \\
\text { Sulphanilamide } \\
\text { (Mg. per } \frac{1}{2} \text { hour) }\end{array}$ \\
\hline $0-\frac{1}{2}$ & 220 & 471 \\
$\frac{1}{2}-1$ & 140 & 317 \\
$1-1 \frac{1}{2}$ & 40 & $\frac{1}{69}$ \\
$1 \frac{1}{2}-2$ & 0 & 115 \\
$2-5$ & 0 & 0 \\
$5-6$ & 0 & \\
\hline
\end{tabular}

TABLE III.-Administration of Sulphonamide E.O.S. by Mouth (Man). Dose, 4 grammes dissolved in water taken between meals at 11 a.m.)

\begin{tabular}{|c|c|c|c|}
\hline \multirow[b]{2}{*}{$\begin{array}{c}\text { Interval after } \\
\text { Administration }\end{array}$} & \multirow[b]{2}{*}{$\begin{array}{l}\text { Vol. of } \\
\text { Urine } \\
\text { (c.cm.) }\end{array}$} & \multicolumn{2}{|c|}{ Rate of Urinary Excretion } \\
\hline & & $\begin{array}{c}\text { Unsplit } \\
\text { Sulphonamide E.O.S. }\end{array}$ & $\begin{array}{c}\text { Free Sulphonamide, } \\
\text { expressed as } \\
\text { Sulphanilamide } \\
\text { (mg. per } \frac{1}{2} \text { hour) }\end{array}$ \\
\hline $\begin{array}{c}0-20 \text { minutes } \\
20-45 \quad ", \\
45-60 \text { ", } \\
1-1 \frac{1}{2} \text { hours } \\
1 \frac{1}{2}-2 \quad ", \\
2-3 \quad " \\
3-5 \quad " \\
5-7 \quad " \\
7-91 \quad "\end{array}$ & $\begin{array}{l}15 \\
15 \\
15 \\
25 \\
25 \\
35 \\
55 \\
50 \\
60\end{array}$ & $\begin{array}{c}\text { Small amount } \\
\text { " } ", \\
\text { None ", } \\
\text { ", } \\
\text { ", }\end{array}$ & $\begin{array}{l}\text { Trace } \\
3 \cdot 0 \\
13 \cdot 4 \\
15 \cdot 5 \\
17 \cdot 0 \\
12 \cdot 0 \\
11 \cdot 8 \\
8 \cdot 6 \\
9 \cdot 2\end{array}$ \\
\hline
\end{tabular}

The excretion of sulphonamide E.O.S. ceased after two hours, but excretion of considerable amounts of sulphanilamide continued for many hours. The rate of excretion was substantially modified by variations in urinary flow. Excretion was decidedly more rapid during water diuresis. This rapid hydrolysis in the 